\title{
EFFECT OF NANO-SiO2 PARTICLES ON PARTIAL DISCHARGE SIGNAL CHARACTERISTICS OF FR3 TRANSFORMER OIL
}

\author{
${ }^{1}$ D. Prasad, ${ }^{2}$ S.Chandrasekar \\ ${ }^{1}$ Research Scholar, Faculty of Electrical Engineering, Anna University Chennai, \\ Sona College of Technology, Salem, Tamilnadu, India. \\ E-mail ID: mani.gd@gmail.com \\ ${ }^{2}$ Dean(R\&D), Head/SonaPERT R\&D Centre, Department of EEE, \\ Sona College Technology, Salem, Tamilnadu, India. \\ E-mail ID:chandrukvt@gmail.com
}

\begin{abstract}
Liquid insulation for high voltage transformer applications based on natural esters derived from abundantly available vegetable oils are becoming popular in recent times. Since these natural ester based oils have environmental advantages and superior thermal performance, electrical utilities are slowly replacing the conventional mineral oils with natural ester based vegetable oils. FR3 oil, which is a soya based natural ester oil with superior dielectric and thermal characteristics, is becoming popular as an alternate insulating medium for high voltage transformers. With recent developments in nanotechnology field, it is possible to enhance the dielectric performance characteristics of natural ester based oils, which is a major constraint for high voltage transformer applications. However few research reports are only available in the area of nanofluids based on natural esters for high voltage insulation applications. In depth analysis and collection of large data base of insulation performance of natural ester based vegetable oils is important to improve the confidence level over nano-fluids based on natural esters. Considering these facts, in the present work, partial discharge characteristics of nano- $\mathrm{SiO}_{2}$ modified $\mathrm{FR} 3$ oil at different electrode configurations are investigated at different \%wt filler concentrations. Important parameters such as partial discharge inception voltage, stable PD formation voltage, partial discharge amplitude at different voltage magnitude and PD signal frequency characteristics are evaluated. From the results, it is observed that the partial discharge performance of FR3 oil is significantly improved with the addition of nano-SiO $\mathrm{S}_{2}$ filler. Since in recent times FR3 oil is commercially used in many transformers, these results will be useful for enhancing the dielectric strength of high voltage transformers.
\end{abstract}

\section{Indexing terms/Keywords}

Transformer, insulation, nanofluid, FR3 oil, partial discharge

\section{INTRODUCTION}

Reliability of electric power system mainly depends on the consistency of high voltage transformers. With the ongoing rise of electric power consumption, it is crucial that electricity supplies should be protected and always available. Any breakdown of transformer results in heavy repair expenses and monetary losses due to the disruption of power supply to customers. Nowadays, preventing the breakdowns and preserving the distribution transformers under excellent in-service condition is an imperative duty before the electrical utilities. A large amount of the distribution transformer breakdowns occur due to long term thermal aging and degradation of liquid insulation.

Mineral oil is being used as a liquid dielectric in transformers for a longer period of time. Liquid insulation for high voltage transformer applications based on natural esters derived from abundantly available vegetable oils are becoming popular in recent times. Since these natural ester based oils have environmental advantages and superior thermal performance, electrical utilities are slowly replacing the conventional mineral oils with natural ester based vegetable oils. FR3 oil, which is a soya based natural ester oil with superior dielectric and thermal characteristics, is becoming popular as an alternate insulating medium for high voltage transformers. A lot of research works are being carried out to enhance the dielectric performance characteristics of natural ester based insulation which is largely affected by aging and environmental factors [1-7] . Chandrasekar et al., [1] analyzed the usage of natural esters as a dielectric fluid for power transformers. In this work, they have identified the breakdown strength and PD characteristics of natural esters as a replacement for mineral oil. Banumathi et al., [3] analyzed the PD characteristics of olive oil and castor oil as an alternating insulating medium for high voltage insulation applications and power transformers. Senthilkumar et al., [7] evaluated the dielectric characteristics of thermally aged corn oil and palm oil as an insulating medium for high voltage applications.

With recent developments in nanotechnology field, it is possible to enhance the dielectric performance characteristics of natural ester based oils, which is a major constraint for high voltage transformer applications. However few research reports are only available in the area of nanofluids based on natural esters for high voltage insulation applications. In depth analysis and collection of large data base of insulation performance of natural ester based vegetable oils is important to improve the confidence level over nano-fluids based on natural esters. Researchers are working towards nanofluid insulation with both mineral oil and vegetable oils with a variety of filler materials at different concentrations. Sankarganesh et al., [9] investigated the corona type PD signal characteristics of nano- $\mathrm{SiO}_{2}$ modified mineral oil at different filler \%wt concentrations. Proper selection of base oil and filler material makes nanofluid more appropriate for transformer applications [8-18]. Dong et al., [11], analyzed the Aluminum-nitride-(AIN)-transformer oil-based nanofluid at different ambient temperatures. They have shown that in comparison to the pure transformer oil, the electrical conductivity of nanofluid containing $0.5 \%$ AIN nanoparticles has increased by 1057 times at $60^{\circ} \mathrm{C}$. T.S.Ramu et al., [12], considered the $\mathrm{AC}, \mathrm{DC}$ and Lightning impulse breakdown characteristics of $\mathrm{Fe}_{3} \mathrm{O}_{4}$ and $\mathrm{SiO}_{2}$ nanofiller added transformer mineral oil

\section{1 | P a g e}


and they have concluded that the dielectric breakdown strength of investigated nanofluids greatly improved under all forms of voltages and of either polarity. In addition, mineral oil top and hot spot temperatures are considerably lowered in nanofluid filled transformers.

However, there are certain key issues to be investigated before applying nanofluid insulation for real time application in transformers. Weakening of transformer oil insulation mainly starts due to the partial discharge (PD) activities, which are caused by the presence of impurities, voids, cavities, air bubbles and conducting metal particles. Hence PD measurement is commonly accepted as one of the key diagnostic technique for understanding the insulation strength of electrical high voltage apparatus. Inside the transformer, PD mainly starts due to the enhancement of local electric field in the oil and paper insulation and it slowly speeds up the degradation and aging of the insulation system. Based on the nature of electric field configuration and the source of occurrence of PD, it can be classified as surface PD and corona PD. Surface discharge PD mostly occurs at the interface of the oil/paper and oil/pressboard interface of insulation. Corona PD mostly occurs at conductor sharp points or protrusions in the oil. Hence PD studies of transformers, both in the laboratory and in the on-field, have created lot of interest among researchers [19-20]. However, reports on PD characteristics of nano ester based fluid insulation are scanty.

Having known this, in this work, PD characteristics of nano ester based insulation prepared with base FR3 oil and nano $\mathrm{SiO} 2$ fillers at different \%wt concentrations was evaluated. Surface discharges and corona discharges were simulated in the laboratory and corresponding PD signal characteristics were measured. Time and frequency characteristics of PD signals were evaluated and compared with pure FR3 oil without any nano filler. Key parameters such as partial discharge inception voltage, partial discharge stable formation voltage and PD pulse amplitude were evaluated.

\section{EXPERIMENTAL WORKS}

In this section, laboratory experimental studies such as preparation of nano-FR3 oil and partial discharge signal generation at different electrode configurations of nano-FR3 oil are discussed in detail.

\subsection{Preparation of Nano-FR3 Oil}

Commercially available FR3 oil (supplied by Cargill India), is used as a base fluid. Silica $\left(\mathrm{SiO}_{2}\right)$ nano particles were supplied by Hefei Jiankun Chemical Industry. Size of less than $80 \mathrm{~nm}$ with a purity greater than $99 \% \mathrm{SiO}_{2}$ was used for making nanofluid. Filler materials were added at $0.01,0.05$ and $0.1 \%$ concentrations by weight for preparing the nanofluids. Magnetic stirring operation and ultrasonication operation were carried out for enhancing the stability of the nanofluid as shown in Figure 1.

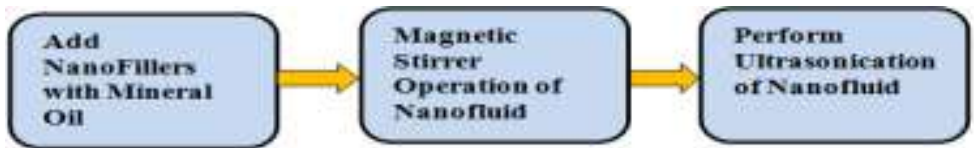

Fig.1. Steps involved in the preparation of nano-mineral oil

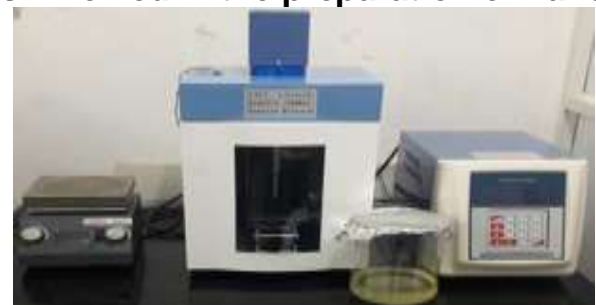

Fig.2 . Photograph of magnetic stirrer and ultrasonicator used in the preparation of nano-FR3 oil

Figure 2 shows the photograph of magnetic stirrer and ultrasonicator used in the preparation of nano-FR3 oil . At first, magnetic stirrer operation is carried out for 45 minutes with required amount of nanofiller material added with the base FR3 oil. This process enhances the dispersal of aggregations in the base FR3 oil. Then ultrasonication is carried out for 20 minutes, which results in a well dispersed nanofluid. From the above two methodology, agglomeration and sedimentation of nanoparticles in the FR3 oil is totally avoided.

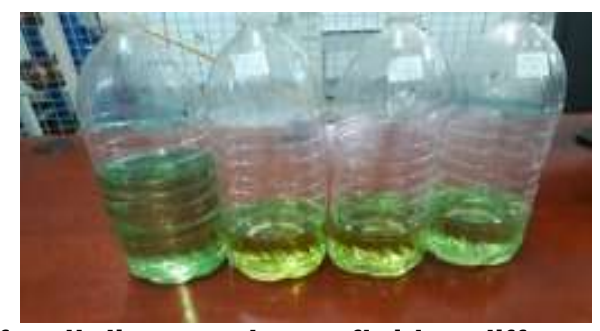

Fig. 3. Photograph of well dispersed nanofluid at different \%wt concentrations 
Table 1. Sample identity of nano-FR3 oil

\begin{tabular}{|c|l|}
\hline Sample Identity & \multicolumn{1}{|c|}{ Detail } \\
\hline A & Pure FR3 oil \\
\hline B & $\mathrm{FR} 3+0.01 \% \mathrm{SiO}_{2}$ \\
\hline C & $\mathrm{FR} 3+0.05 \% \mathrm{SiO}_{2}$ \\
\hline D & $\mathrm{FR} 3+0.1 \% \mathrm{SiO}_{2}$ \\
\hline
\end{tabular}

Figure 3 shows the photograph of the well dispersed nanofluid prepared in the laboratory at different \%wt concentrations. According to the \%wt concentration of $\mathrm{SiO} 2$ nanofiller material added in the base FR3 oil, the samples were given identity as $\mathrm{A}, \mathrm{B}, \mathrm{C}$ and $\mathrm{D}$ as shown in the Table 1.

\subsection{PD Signal Generation using Needle-Plane and Rod-Plane Electrode Configuration}

In a transformer, partial discharge mainly occurs due to the local electric field enhancement in the voids, cavities, bubbles and metal particles. Based on the source of PD and electric field configuration, PD activities can be classified as corona $\mathrm{PD}$ and surface PD. In order to simulate corona PD in the laboratory, needle-plane electrode configuration was used and similarly, in order to generate surface PD, rod-plane electrode configuration was used. Figure $4 a$ and $4 b$ shows the electrode configuration used to simulate corona discharges and surface discharges respectively. Figure $5 \mathrm{a}$ and $5 \mathrm{~b}$ shows the photograph of laboratory test cell setup used to produce corona discharges with needle-plane electrode arrangement and surface discharges with rod-plane electroe arrangement respectively.

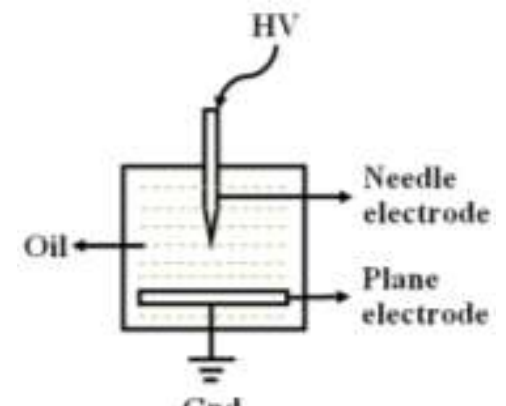

(a)

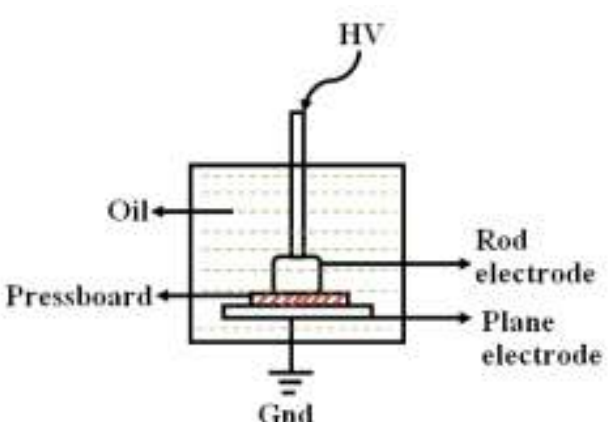

(b)

Fig. 4. (a) Test cell used for the generation of (a) corona discharge with needle-plane electrode configuration (b) surface discharge with rod-plane electrode configuration

Corona discharges were produced with a needle of $20 \mu \mathrm{m}$ tip radius. Gap distance between the electrodes was maintained at $5 \mathrm{~mm}$. Surface discharges were produced with a rod electrode of $10 \mathrm{~mm}$ diameter and $10 \mathrm{~mm}$ height. Bottom plane electrode is of $25 \mathrm{~mm}$ diameter and $10 \mathrm{~mm}$ height. Gap distance between the electrodes was maintained at $5 \mathrm{~mm}$. Pressboard material of thickness $5 \mathrm{~mm}$ was kept in between the rod electrode and plane electrode. In the test cell, high voltage was connected to the top electrode and bottom electrode was solidly grounded.
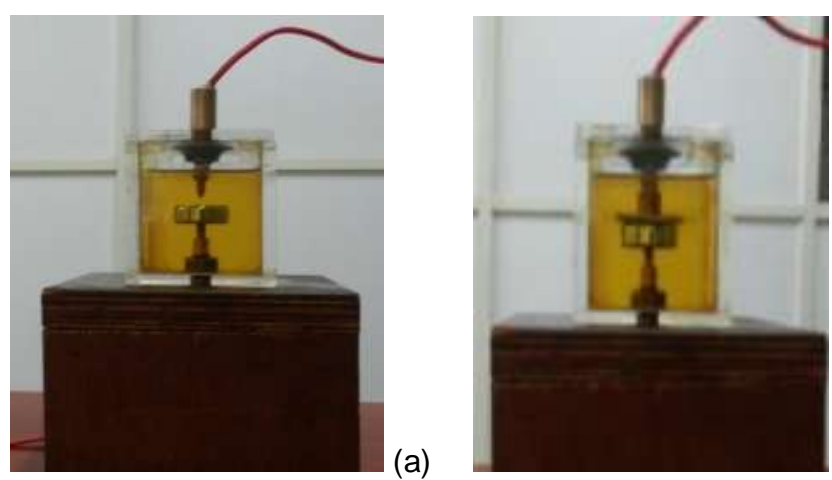

(b)

Fig. 5. (a) Photograph of test cell used for the generation of PD (a) corona discharge with needle-plane electrode configuration (b) surface discharge with rod-plane electrode configuration 


\subsection{Partial Discharge Detection and Measuring Setup}

Partial discharge measurement is carried out as per IEC 60270 test procedures. Figure 6 shows the schematic diagram of experimental setup used for partial discharge measurement in the laboratory. The test cell is energized from a step up transformer which can supply voltage upto $100 \mathrm{kV}$. High voltage transformer primary is energized from a control panel connected with a $230 \mathrm{~V}$ AC supply. In order to protect the high voltage source from over current, a current limiting resistor $\mathrm{R}$ is used. Test cell is filled with nano-mineral oil prepared at different \%wt concentrations.

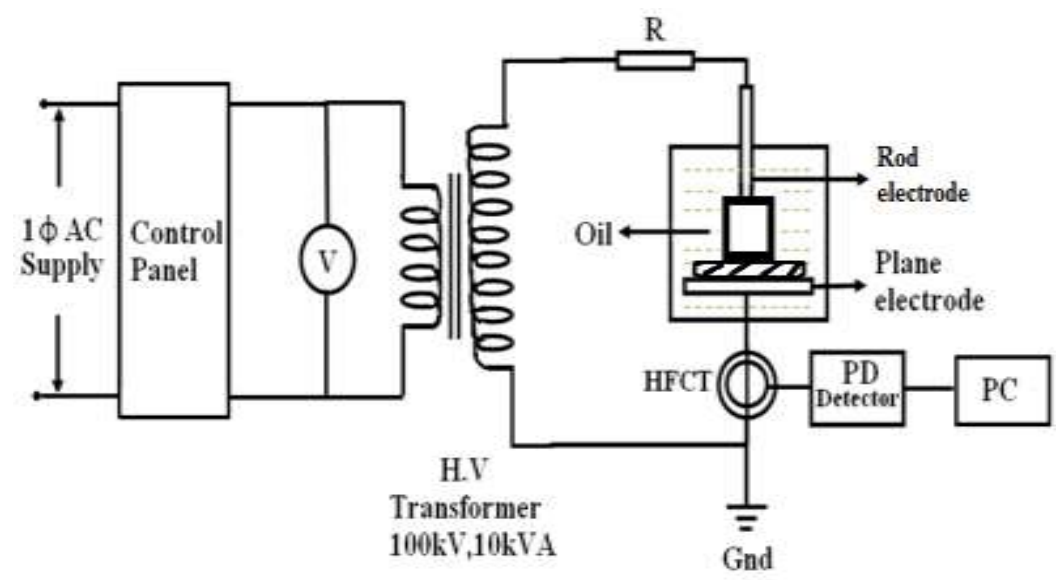

Fig. 6. Schematic diagram of the experimental setup for PD measurement

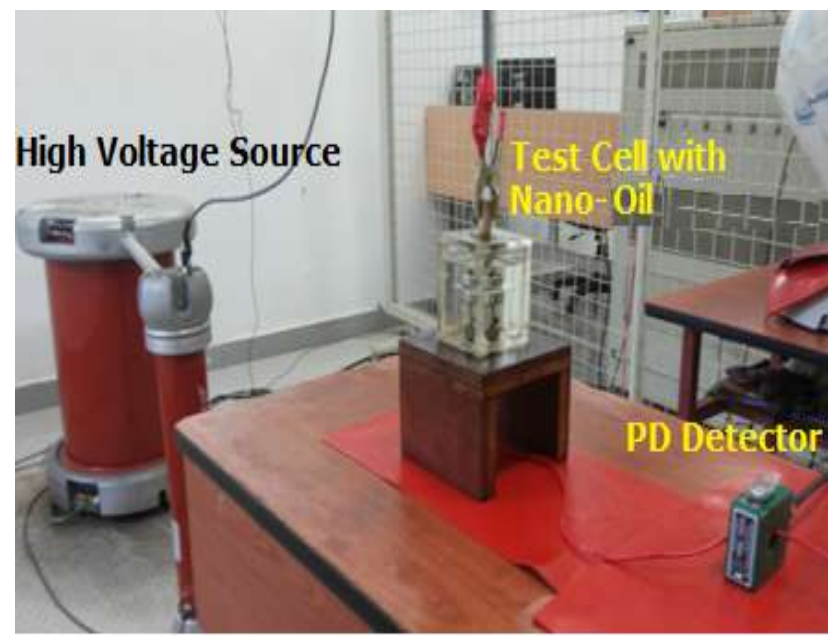

Fig. 7. Photograph of the laboratory experimental setup for PD measurement

Figure 7 shows the photograph of the laboratory experimental setup used for PD measurement. High frequency current transformer (HFCT) was used for capturing PD signals and it is a clip on device clamped on the ground connection of the test cell. Frequency bandwidth of HFCT is $50 \mathrm{MHz}$, which is adequate to cover the entire range of PD. PD detector is connected with Agilent Digital Oscilloscope, $200 \mathrm{MHz}, 2 \mathrm{GSa} / \mathrm{sec}$ for visualization of the PD signals. The PD pulses were sent to a remote PC for further processing.

\section{RESULTS AND DISCUSSION}

\subsection{Evaluation of Inception and Stable PD formation voltage at Corona Discharges}

In general, Partial discharge inception voltage (PDIV) is evaluated as the lowest voltage at which observable PD pulses appear on the PD measuring system. In order to evaluate PDIV, supply voltage is increased in steps from $1 \mathrm{kV}$, up to the level at which the PDIV is reached. The PDIV value is defined as the value of applied voltage at which at least one PD pulse is detected over an interval of 10 minutes. Pompili et al., [20] have reported that determination of PDIV in the case of liquid dielectrics is difficult because PD pulses appear in pulse bursts and their occurrence rate is more erratic. Similarly, another important parameter is the stable PD formation voltage, which is evaluated as the voltage at which formation of PD pulses are stable over an interval of 10 minutes. In order to evaluate stable PD formation voltage, it is necessary to exceed significantly the PDIV value of any liquid dielectrics and applied voltage should be slowly increased in steps to evaluate stable PD voltage. During each test, PD signals were acquired under steady state conditions with a time delay of 1 minute after voltage application. 


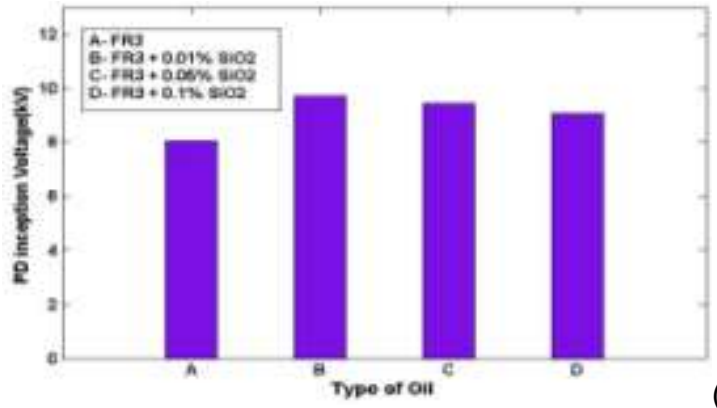

(a)

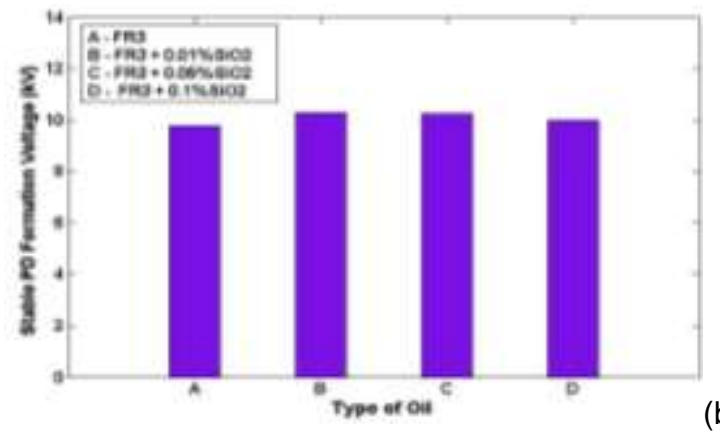

(b)

Fig. 8. (a) Partial discharge inception voltage (b) Stable PD formation voltage of nano $\mathrm{SiO}_{2}$ modified FR3 oil at different \%wt concentrations at corona discharge PD

During the test, PD signals were measured at stable condition after voltage application and a set of 5 PD measurements were carried out at each voltage level in order to extract the $95 \%$ of confidence level. Figure 8 a shows the PDIV of FR3 nanofluid samples measured at $5 \mathrm{~mm}$ gap distance between the electrodes at different \%wt concentration of $\mathrm{SiO}_{2}$ nanofiller. In general, it is noticed that addition of SiO2 nanofillers on the FR3 oil showed higher PDIV when compared with pure FR3 oil without any nanofillers. In this case, $20 \%$ increase in PDIV value is noticed with $0.01 \%$ wt samples. However, it is also noticed that $0.1 \%$ wt concentration of $\mathrm{SiO} 2$ nanofillers show slight reduction in PDIV value. Figure $8 \mathrm{~b}$ shows the stable PD formation voltage of FR3 nanofluid with $\mathrm{SiO}_{2}$ material at different \%wt concentrations with needle-plane electrode configuration. It is noted that, stable PD formation occurs above $8 \mathrm{kV}$ for the present test configuration at all samples. When compared with conventional FR3 oil, nanofluids show $5 \%$ increase in stable PD formation voltage. However, stable PD formation voltage has little influence on the increase in \%wt $\mathrm{SiO}_{2}$ nanofiller concentration.

\subsection{Evaluation of Inception and Stable PD formation voltage at Surface Discharges}

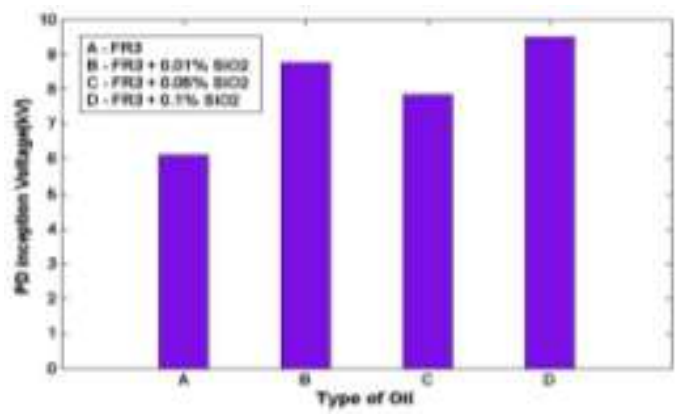

(a)

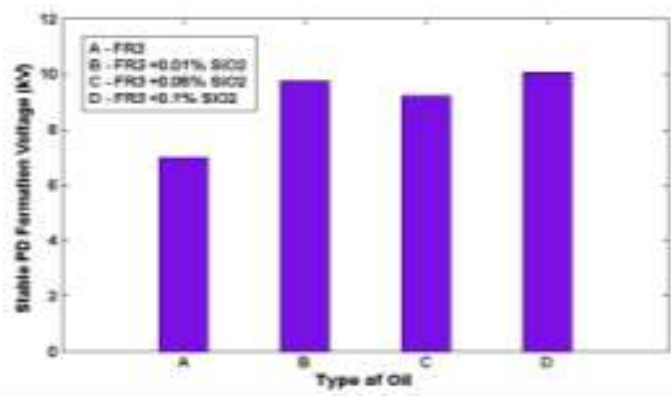

(b)

Fig. 9. (a) Partial discharge inception voltage (b) Stable PD formation voltage of nano $\mathrm{SiO}_{2}$ modified FR3 oil at different \%wt concentrations at surface discharge PD 
Figure 9a shows the PDIV of FR3 nanofluid samples at different \%wt concentration of $\mathrm{SiO}_{2}$ nanofiller using rod-plane electrode configuration. In general, it is noticed that addition of SiO2 nanofillers on the FR3 oil showed higher PDIV when compared with pure FR3 oil without any nanofillers. In particular, $0.1 \%$ wt concentration sample showed higher PDIV than other tested samples. In this case, $50 \%$ increase in PDIV value is noticed with $0.1 \%$ wt and $0.01 \%$ wt samples. However, it is also noticed that $0.05 \%$ wt $\mathrm{SiO} 2$ nanofiller samples show slight reduction in PDIV value. Figure 9b shows the stable PD formation voltage of $\mathrm{FR} 3$ nanofluid with $\mathrm{SiO}_{2}$ material at different \%wt concentrations with rod-plane electrode configuration. It is noted that, stable PD formation occurs above $9 \mathrm{kV}$ for the present test configuration at all nanofluid samples, whereas for pure FR3 oil it lies below $7 \mathrm{kV}$. When compared with pure FR3 oil, nanofluids show $30 \%$ increase in stable PD formation voltage.

\subsection{Evaluation of Corona discharge amplitude at different Voltage Magnitude}

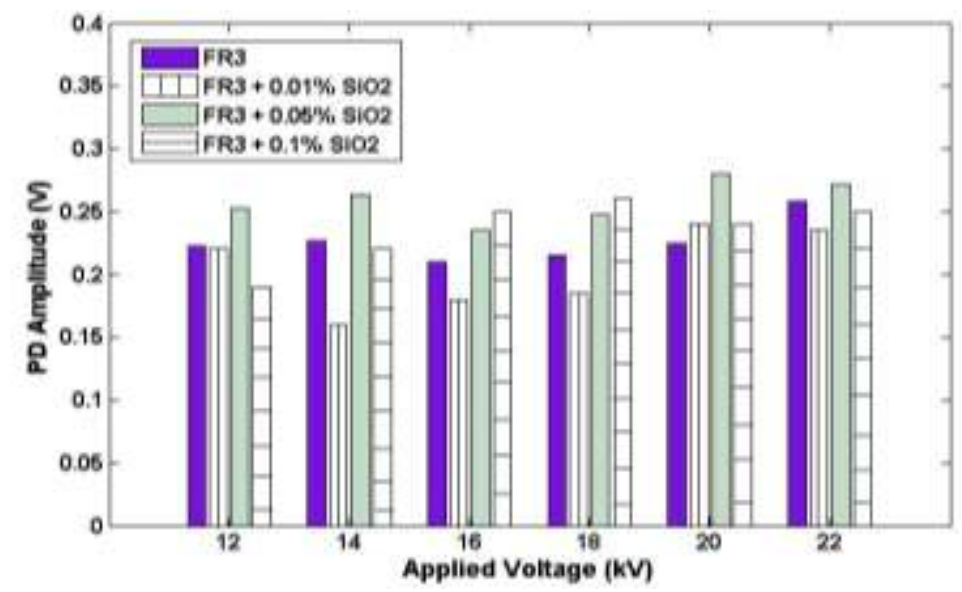

Fig. 10. Comparison of average corona PD amplitude of nano-FR3 oil specimens obtained at different voltage stress

Partial discharge activity in a liquid insulation is highly random process and PD pulses appear in pulse bursts, with varying repetition rate. In this study, all the nano-FR3 oil samples were thermally treated and ensured that they are free of moisture content before starting the PD experiment. Hence the PD amplitude variations will be mainly dependent on the applied voltage stress and it will be independent of external factors. Figure 10 shows the comparison of average corona PD amplitude of nano-FR3 oil specimen obtained at different voltage stress. Average PD amplitude is evaluated by taking the average value of PD amplitudes of several PD pulses captured at the same voltage stress. It is noticed that pure FR3 oil (specimen A) shows slightly increase in average PD amplitude when compared with $0.01 \%$ wt concentration specimen. However, considerable increase in average PD amplitude is observed with sample $C$ and $D$ at all voltage stresses when compared with sample A and B. It is also observed that type B specimen shows superior performance when compared with all other tested oil specimens. This shows that lower weight concentration of nanofiller should be considered for taking better advantage of nanofiller materials for transformer applications. However, this has to be confirmed with several other dielectric characteristic tests before concluding for real time applications. Concentration above $0.05 \%$ wt has little influence on improvement in PD amplitude characteristics, which may be due to agglomeration of nanoparticles above certain \%wt concentration, which needs to be confirmed with further studies.

\subsection{Evaluation of Surface discharge amplitude at different Voltage Magnitude}

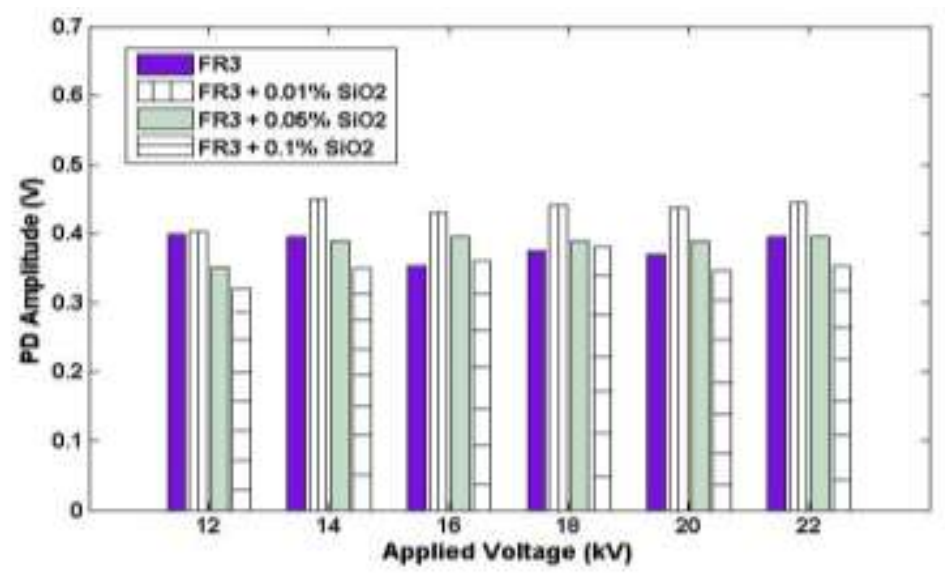

Fig. 11. Comparison of average surface PD amplitude of nano-FR3 oil specimens obtained at different voltage stress 
Figure 11 shows the comparison of average surface PD amplitude of nano-FR3 oil specimen obtained at different voltage stress. It is noticed that pure FR3 oil (specimen A) shows slightly lower average PD amplitude at above $15 \mathrm{kV}$ applied voltage. At lower voltage levels such as 12 and $14 \mathrm{kV}$, performance of sample $\mathrm{D}$ is better. Significant increase in average PD amplitude of sample B is observed at all voltage stresses when compared with other specimens. In the case of nanofluid specimens, it is noted that type $D$ specimen shows superior performance when compared with other specimens. These results should be confirmed with space charge accumulation characteristics studies of oil and pressboard interface of FR3 nanofluid insulation at different voltage stresses.

\subsection{Influence of Nano Particle on the PD Signal Waveshape and Frequency Spectrum at Corona Discharges}
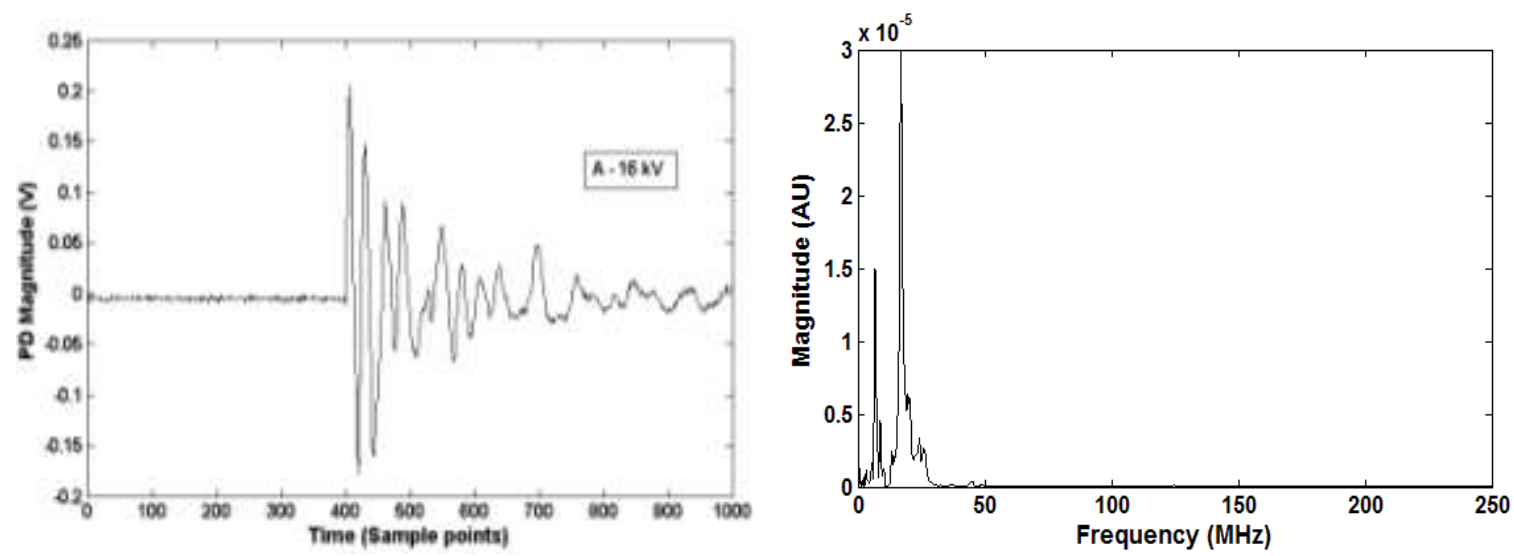

(a)
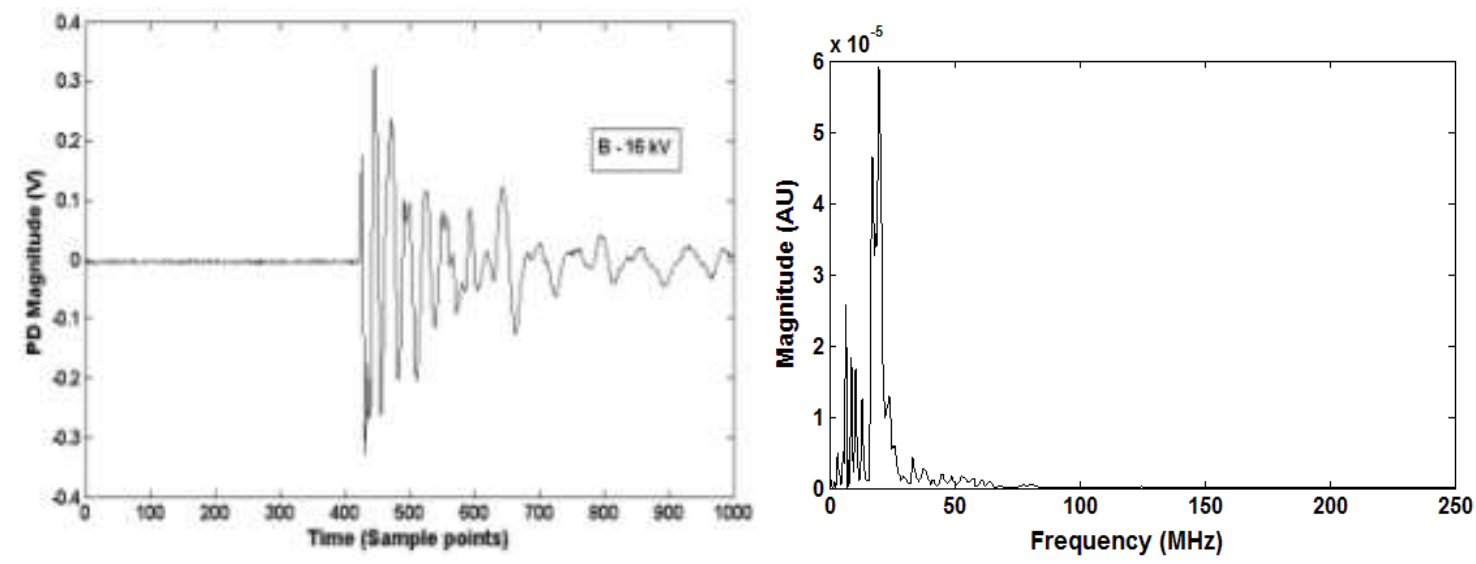

(b)
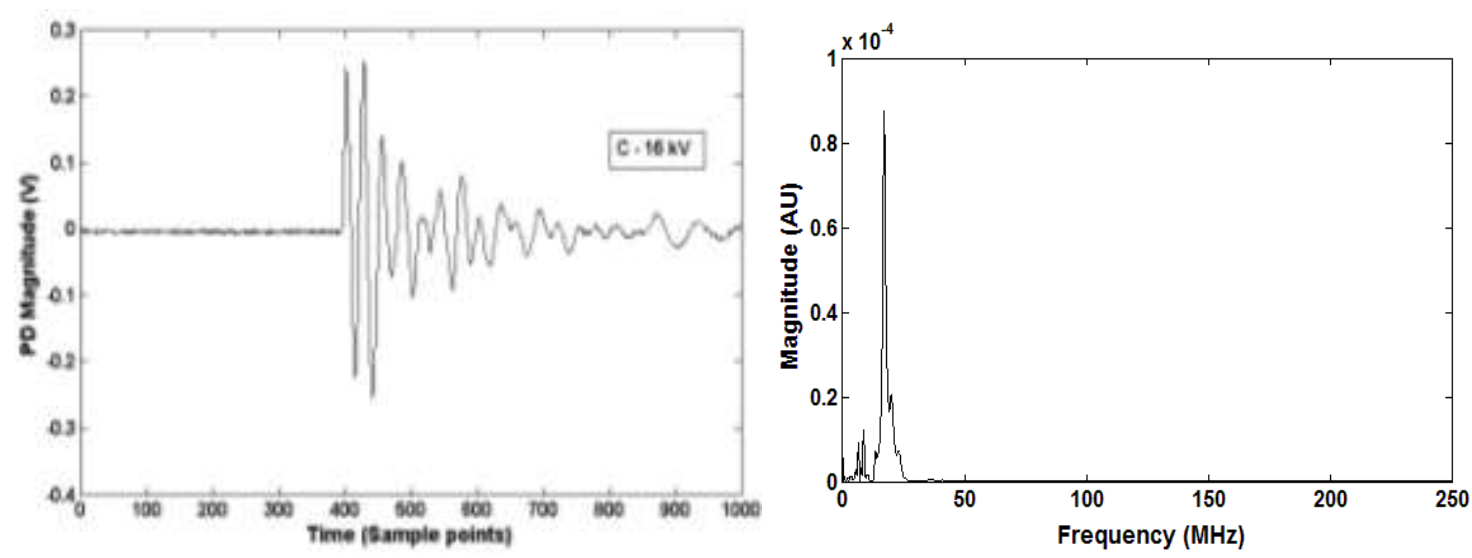

(c) 

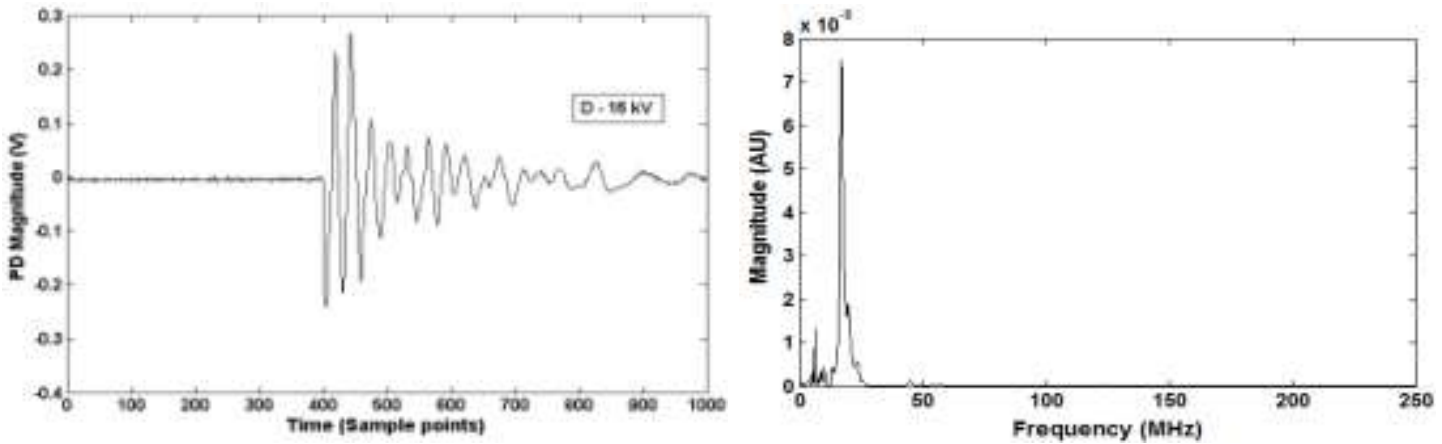

(d)

Fig. 12. Typical (a) PD signal, left (b) corresponding frequency spectrum , right side of FR3 nano fluid specimens at $16 \mathrm{kV}$ applied voltage with needle-plane electrodes

In the case of partial discharge signal analysis, it is always important to understand the time and spectral characteristics of each PD signal at different electrode configurations. Imamovic et al [19] have shown that there exist significant differences in frequency spectrum of the PD signals while simulating corona discharges in the case of transformer oils. Figure 12 shows the typical PD signals and corresponding frequency spectrum of nano-FR3 oil specimen obtained at needle-plane electrode configuration at $16 \mathrm{kV}$ applied voltage. Left side figure shows the PD signal and right side figure shows its frequency spectrum. From the visual inspection of PD signal waveform, it is noticed that there is no big difference in waveshape of nanofluid specimens when compared with pure FR3 oil. However, a slight increase in peak value of PD signal is noticed in the case of nanofluid specimens. In the spectral characteristics, $X$ axis shows the frequency value in $\mathrm{MHz}$ and $\mathrm{Y}$-axis shows the corresponding magnitude of the signal in frequency domain. It is seen that the peak value of frequency bandwidth occurs at around $25 \mathrm{MHz}$ for all test specimens. Small peaks are also observed at $10 \mathrm{MHz}$. Peak value of conventional mineral oil is slightly lower when compared with nano-FR3 oil specimens. However, since the peak values are in the order of $10^{-5}$, these variations are less significant.

\subsection{Influence of Nano Particle on the PD Signal Waveshape and Frequency Spectrum at Surface Discharges}
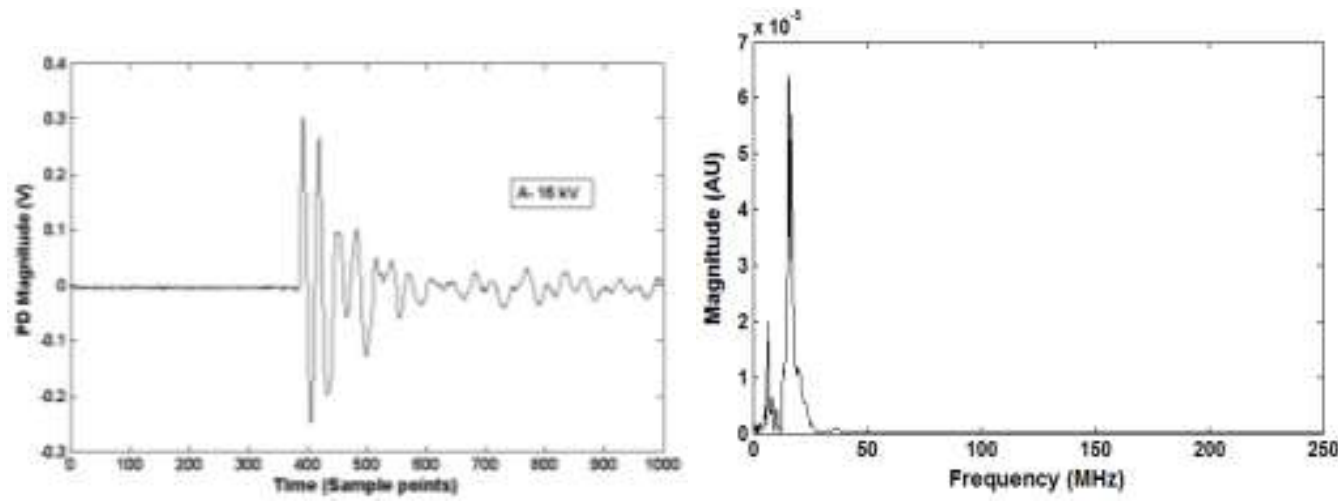

(a)
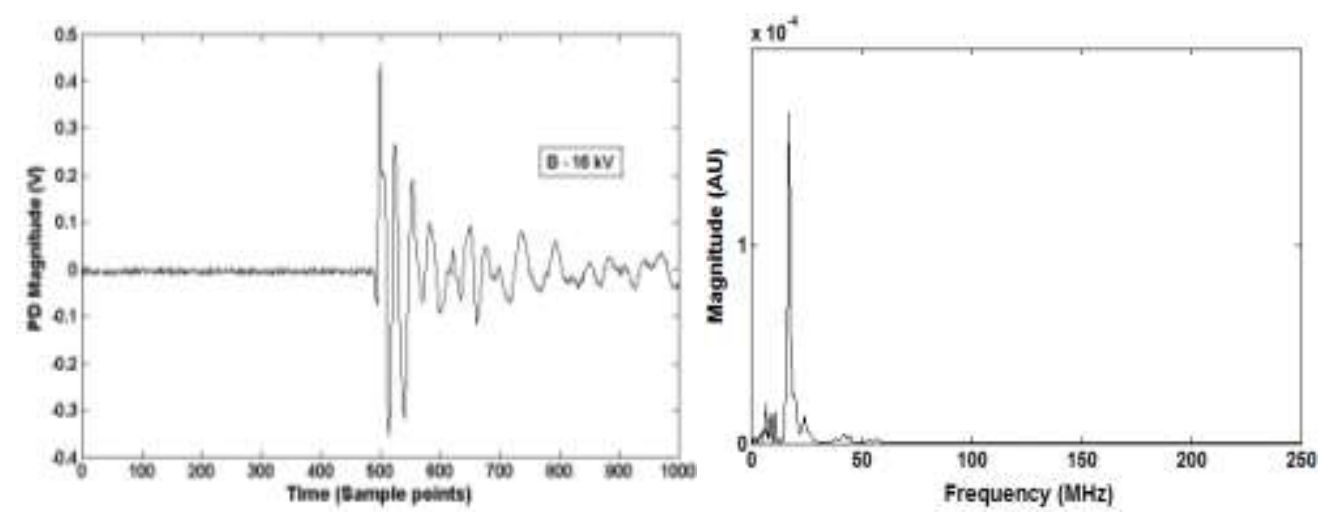

(b) 

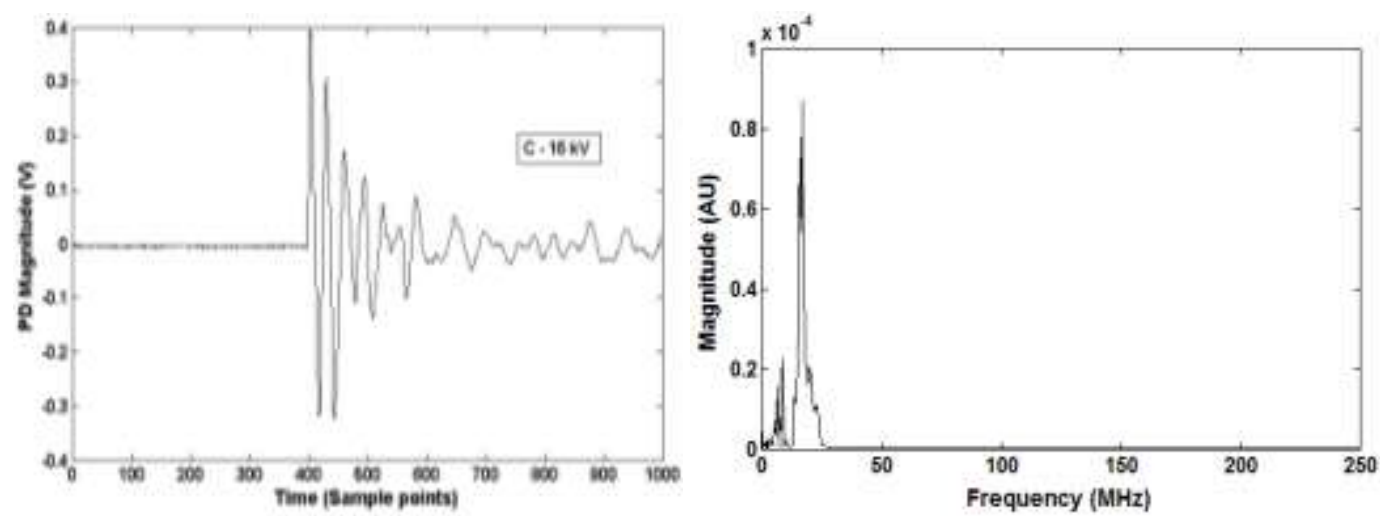

(c)
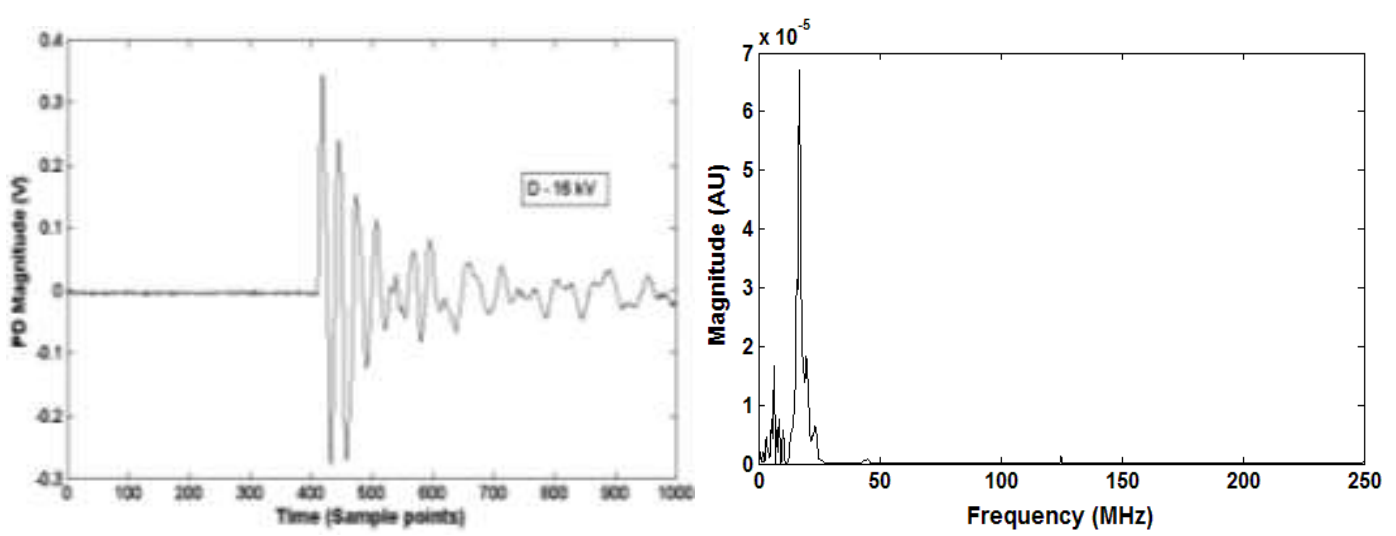

(d)

\section{Fig. 13. Typical (a) PD signal, left (b) corresponding frequency spectrum, right side of FR3 nano fluid specimens at $16 \mathrm{kV}$ applied voltage with rod-plane electrodes}

Figure 13 shows the typical PD signals and corresponding frequency spectrum of nano-FR3 oil specimen obtained at rodplane electrode configuration at $16 \mathrm{kV}$ applied voltage. Left side figure shows the PD signal and right side figure shows its frequency spectrum. From the visual inspection of PD signal waveform, it is noticed that there is no big difference in waveshape of nanofluid specimens when compared with pure FR3 oil, which is in similar line with corona PD results. However, a slight increase in peak value of PD signal is noticed in the case of nanofluid specimens. In the spectral characteristics, $\mathrm{X}$ axis shows the frequency value in $\mathrm{MHz}$ and $\mathrm{Y}$-axis shows the corresponding magnitude of the signal in frequency domain. It is seen that the peak value of frequency bandwidth occurs at around $25 \mathrm{MHz}$ for all test specimens. Small peaks are also observed at $10 \mathrm{MHz}$. Peak value of conventional mineral oil is slightly lower when compared with nano-FR3 oil specimens. However, since the peak values are in the order of $10^{-5}$, these variations are less significant.

\section{CONCLUSION}

Analysis of PD signal characteristics of nano-FR3 oil at different \%wt concentration of nano $\mathrm{SiO}_{2}$ filler material has been presented in this paper. Corona discharges and surface discharges were generated in the laboratory using needle-plane and rod-plane electrode configuration respectively and PD signals were measured at different applied voltage stress. It is observed that partial discharge inception voltage and stable PD formation voltage has significantly improved for nano-FR3 oils when compared with pure FR3 oil. From the analysis of individual PD signals at both low and high voltage stress above PDIV it is noticed that the performance of nano-FR3 oil is comparable with conventional FR3 oil. Overall performance of $0.01 \%$ wt concentration nano-FR3 oil is good when compared with other \%wt concentrations. These results clearly shows that addition of nano- $\mathrm{SiO}_{2}$ fillers in the base $\mathrm{FR} 3$ oil will certainly improve its PD performance characteristics. These preliminary PD data of nano-FR3 oil will be useful for electrical utilities and transformer manufacturers to develop better condition monitoring systems for transformers.

\section{Acknowledgements}

Author (S.Chandrasekar) would like to sincerely thank the CPRI, Bangalore for providing financial support through RSOP scheme for carrying out the research activities on nanofluid insulation for power transformer applications. Authors would also like to thank Cargill for providing oil samples. 


\section{REFERENCES}

1. Chandrasekar,S and Gian Carlo Montanari, "Analysis of Partial Discharge Characteristics of Natural Esters as Dielectric Fluid for Electric Power Apparatus Applications", IEEE Transactions on Dielectrics and Electrical Insulation, Vol.21, No.3 pp.1251-1259, 2014.

2. Martin, N. Lelekakis, W.Guo, and Y.Odarenko, "Further Studies of a Vegetable-Oil-Filled Power Transformer", IEEE Electr. Insul. Mag., vol.27, no.5, pp. 6-13, 2011.

3. Banumathi, S. and Chandrasekar, S, 2015. Aging effect on Partial Discharge Characteristics of Olive oil as an Alternative Liquid Insulating Medium. Research Journal of Applied Sciences, Engineering and Technology, vol. 9, no. 9, 745-754.

4. G.Ramakrishna Prabu and S.Chandrasekar, "Classification of Single PD Sources of HV Transformer Insulation Faults using PRPD Pattern Features and ANN Approach", Asian Journal of Research in Social Sciences and Humanities, Vol. 6, No. 8, pp. 1935-1952, August 2016

5. Banumathi, S. and Chandrasekar, S. 2013. Analysis of Partial Discharge Characteristics of Olive and Castor Oil as Dielectric Medium for HV Applications. International Review of Electrical Engineering (I.R.E.E.), vol. 8, no.6, 18821889.

6. Banumathi, S. and Chandrasekar, "Analysis Of Breakdown Strength And Physical Characteristics Of Vegetable Oils For High Voltage Insulation Applications", Journal of Advances in Chemistry, Vol. 12, No. 16, November 2016, pp. 4902-4912.

7. S.Senthilkumar, B.Karthik and S.Chandrasekar, "Investigations on PD Characteristics of Thermal aged Palm and Corn Oil for Power Transformer Insulation Applications", Journal of Electrical Engineering and Technology, Vol.9, No.5 pp. 1660-1669,Sep 2014.

8. Huifei Jin,Thomas Andritsch, loannis A. Tsekmes, Roman Kochetov, Peter H.F. Morshuis, Johan J. Smit, "Properties of Mineral Oil based Silica Nanofluids", IEEE Transactions on Dielectrics and Electrical Insulation, Vol. 21, No. 3, pp.1100-1108, 2014.

9. R. Sankarganesh, R. Shivakumar and S. Chandrasekar, "Analysis of Partial Discharge Signal Characteristics of NanoMineral Oil for Transformer Condition Monitoring Applications", Asian Journal of Research in Social Sciences and Humanities, Vol. 6, No. 7, pp. 341-357, July 2016.

10. Jian Li, Zhaotao Zhang,Ping Zou and Stanislaw Grzybowski, "Preparation of a Vegetable Oil-Based Nanofluid and Investigation of Its Breakdown and Dielectric Properties", IEEE Electrical Insulation Magazine, Vol. 28, No. 5, pp.43$50,2012$.

11. Dong, M, L. P. Shen, H. Wang, H. B. Wang, and J.Miao, "Investigation on the Electrical Conductivity of Transformer Oil-Based AIN Nanofluid", Journal of Nanomaterials, Hindawi Publishing Corporation ,Volume 2013, Article ID 842963 pp.1-7, 2013.

12. Ramu,T.S., B.K.Keshavan, K.N.Balasubramanya Murthi, "Application of a Class of Nano fluids to improve the Loadability of Power Transformers", IEEE 10th International Conference on the Properties and Applications of Dielectric Materials, July 24-28,2012, Bangalore, India, 2012.

13. Rongsheng Liu, Leif A.A. Pettersson, Tommaso Auletta, Olof Hjortstam ,2011, "Fundamental Research on the Application of Nano Dielectrics to Transformers", IEEE International Conference, pp.423-427.

14. Y. Du, Y. Lv, C. Li, M. Chen, J. Zhou, "Effect of electron shallow trap on breakdown performance of transformer oilbased nano fluids", J. Appl. Phys., Vol.110, pp. 104104-104104-4, 2011.

15. Anandhan Elansezhiyan, S. Chandrasekar," Investigations on Dielectric Properties of Nano SiO2-Mineral Oil for Transformer Insulation Applications", Asian Journal of Research in Social Sciences and Humanities, Vol. 6, No. 10, October 2016, pp. 1783-1795.

16. Anandhan Elansezhiyan, S. Chandrasekar," Understanding The Lightning Discharge Withstand And Breakdown Characteristics Of Nano SiO2 Modified Mineral Oil For Transformer Applications", Journal of Advances in Chemistry, Vol. 12, No. 19, November 2016, pp. 5200-5208.

17. R. Liu, L. A. A. Pettersson, T. Auletta and O. Hjortstam, "Fundamental research on the application of nano dielectrics to transformer",IEEE conf. Electr. Insul. Dielectric. Phenomena, pp.423-427,2011.

18. D. Prasad, S. Chandrasekar ," Investigations on Dielectric Performance Characteristics of Natural Ester based NanoFluids for Power Transformer Applications", Asian Journal of Research in Social Sciences and Humanities, Vol. 6, No. 11, November 2016, pp. 1146-1157.

19. D.Imamovic, K.X.Lai, N.A.Muhamad, B.T.Phung and T.R.Blackburn, "Partial Discharge and Dissolved Gas Analysis in Bio-Degradable Transformer Oil”, in Proc. of Cigre 16, pp.1-7, Brugge, 2007.

20. M.Pompili, C.Mazzetti and R.Bartnikas, "Partial Discharge Pulse Sequence Patterns and Cavity Development Times in Transformer Oils under ac Conditions", IEEE Trans. Dielectr. Electr. Insul., vol. 12, no. 2, pp. 395-403, 2005. 